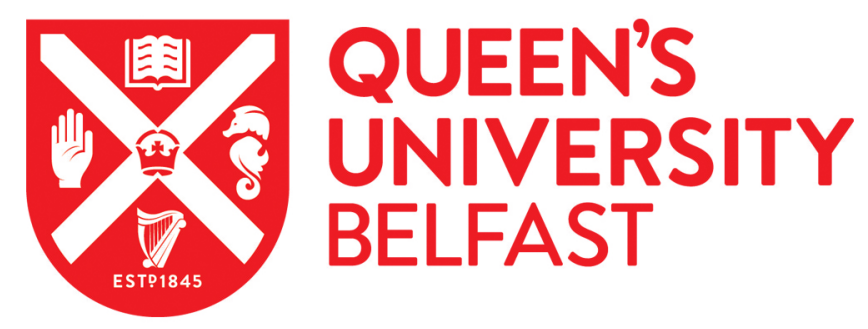

\title{
An analytical delamination model of drilling aramid fiber-reinforced plastics by brad drill
}

Liu, S., Tao, Y., Liu, C., Jin, Y., Sun, D., \& Shen, Y. (2020). An analytical delamination model of drilling aramid fiber-reinforced plastics by brad drill. The International Journal of Advanced Manufacturing Technology . https://doi.org/10.1007/s00170-020-05628-9

\section{Published in:}

The International Journal of Advanced Manufacturing Technology

\section{Document Version:}

Peer reviewed version

Queen's University Belfast - Research Portal:

Link to publication record in Queen's University Belfast Research Portal

\section{Publisher rights}

Copyright 2020 Springer Nature. This work is made available online in accordance with the publisher's policies. Please refer to any applicable terms of use of the publisher.

\section{General rights}

Copyright for the publications made accessible via the Queen's University Belfast Research Portal is retained by the author(s) and / or other copyright owners and it is a condition of accessing these publications that users recognise and abide by the legal requirements associated with these rights.

Take down policy

The Research Portal is Queen's institutional repository that provides access to Queen's research output. Every effort has been made to ensure that content in the Research Portal does not infringe any person's rights, or applicable UK laws. If you discover content in the Research Portal that you believe breaches copyright or violates any law, please contact openaccess@qub.ac.uk. 


\title{
An analytical delamination model of drilling aramid fiber reinforced plastics by brad drill
}

\author{
Sinan Liu ${ }^{\mathrm{a}, \mathrm{b}}$, Tao Yang ${ }^{\mathrm{a}, *}$, Chang Liu ${ }^{\mathrm{a}}$, Yan Jin ${ }^{\mathrm{b}}$, Dan Sun ${ }^{\mathrm{b}}$, Yifei Shen ${ }^{\mathrm{a}}$ \\ ${ }^{a}$ School of Mechanical Engineering, Tiangong University, Tianjin 300387, China \\ b School of Mechanical and Aerospace Engineering, Queen's University Belfast, BT9 \\ $5 \mathrm{AH}, \mathrm{UK}$ \\ *Corresponding author E-mail address: yangtao@tjpu.edu.cn (T. Yang)
}

\begin{abstract}
Aramid fiber reinforced plastic (AFRP) composites have been widely used in aerospace, defense, and automotive industries. Proven by practical experience, a brad drill can effectively reduce drilling-induced damages in drilling of AFRP due to its unique tool geometry. While the delamination mechanism and the associated analytical model of the brad drill are crucial for improving hole quality and machining accuracy, these aspects were rarely discussed in the literature. This study reports the first work on the delamination mechanism in the context of drilling AFRP by brad drill through detailed analysis of tool/material interactions. A novel analytical model of the critical thrust force $(\mathrm{CTF})$ is proposed for the prediction of both hole wall and hole exit delamination. Model analysis shows that the hole wall delamination is more likely to occur prior to hole exit delamination when the remaining uncut material is thinner than $0.38 \mathrm{~mm}$. When the thickness of the uncut material is greater than $0.4 \mathrm{~mm}$, no hole wall delamination will occur. Through analysis of thrust force components generated by different cutting edges on the total CTF, the contribution of cutting spurs on the thrust force is found to be more effective at suppressing hole wall delamination. The model and the associated experimental validation of this study have laid down a foundation for the design and optimization of drill bits in the future.
\end{abstract}

\section{Keywords}

AFRP composites, Brad drill, Delamination, Critical thrust force, Drilling 


\section{Introduction}

The excellent properties of aramid fiber reinforced plastic (AFRP) composites, such as high toughness and chemical resistance [1], have enabled their wide applications in aerospace, automotive, and defense industries. To date, drilling is still considered as the most pivotal hole-making process in composite component assemblies due to its cost effectiveness [2]. However, drilling of AFRP remains a challenge due to the inherent anisotropic multiphase structure of the material [3]. Drilling-induced damages, such as thermal degradation, fiber bundle tearing, and delamination, are common in the AFRP hole making processes. [4-5].

Delamination, the most undesirable drilling induced damage, can drastically deteriorate the mechanical strength and stiffness of composite laminates with open holes, hence limiting their load bearing capacity and tensile fatigue endurance [6-7]. Delamination repair is time consuming (5-6 hours [8]) and requires additional manufacturing resource. With the aim of minimizing drilling induced delamination damage, researchers have studied delamination phenomena during drilling of fiber reinforced plastics (FRP). Interlaminar failure has been identified around the tool/material contact area due to the localized bending induced by highly concentrated stress [9-10]. Considering the thickness of the uncut material and its associated bending stiffness, the laminate can withstand the thrust force at the early stage of the drilling process. However, as the bending stiffness of the uncut material gradually decreases during drilling, delamination can occur when the thrust force imposed on the uncut material exceeds a critical value.

In the literature, an effective indicator for delamination prediction, critical thrust force (CTF) has been proposed for FRP drilling with twist drills. Ho-cheng and Dharan [11] developed the first CTF model by assuming isotropy of the FRP laminates and the point load generated by the drill. Later, with assumptions made on the stress analysis, applied loads on the uncut material, and the geometry of the delamination crack, extensive work has been carried out to improve the model accuracy. Upadhyay et al. [12] compared the effects of point and distributed loads, small and large deformations 
of the uncut material on the delamination model of composite laminates. Considering the orthotropic properties of unidirectional carbon reinforced plastics (CFRP) laminates, Jain and Yang [13] introduced an elliptical plate model which is more accurate in describing the delamination region during drilling. In order to present an analytical model for predicting the CTF and the corresponding critical feed rate, Karimi et al. [14] combined the cutting force model and the delamination model based on the mechanics of oblique cutting, linear elastic fracture mechanics (LEFM), and classical plate theory. The model verified the feasibility of using optimal feed rate to achieve delamination free drilling. Saoudi et al. [15] considered the coupling of laminate bending and stretching, and proposed an analytical CTF prediction model for drilling multidirectional CFRP laminates with an un-symmetrical stacking sequence. More recently, analytical models have been derived based on the thermo-mechanical formulation [16], mixed mode strain energy release rates in the delamination zone $[8,17]$, and generalized composed loading (uniform / triangular loading with additional point load) [18].

The above analytical models are all based on the tool geometry of conventional twist drills. However, owing to the inherent heterogeneity and anisotropy of FRP composites, a twist drill often leads to poor hole quality featuring matrix cracking, fiber pullouts, and delamination [19-20]. To achieve better hole quality and machining accuracy, other tools with special tool geometries [21-25] and modified cutting force distribution [2627] have been investigated. For instance, brad drills has been investigated by several researchers in the context of AFRP drilling. Di Ilio et al. [28] investigated the relationships between the thrust force / torque and the tool geometry by analyzing the brad drill cutting mechanism. Díaz-Álvarez [29] compared the cutting performance of a brad drill and a twist drill during drilling of AFRP laminates and found that the brad drill can better suppress the delamination and fuzzing under low feed rates and high cutting speeds. Liu et al., further confirmed that the brad drill can effectively restrain the concession and deformation of aramid fibers and improve the shearing action of the cutting edge [30]. Despite the promising experimental results seen in drilling of AFRP deploying brad drills, the detailed delamination mechanism and the corresponding analytical model associated with such process are still lacking. 
In this study, two deamination conditions, namely, hole wall delamination and hole exit delamination have been thoroughly analyzed. Taking into account the actual tool / material contacts, a novel delamination model which describes the thrust force components generated by the brad point, cutting lips, and cutting spurs of the brad drill has been proposed to predict the CTF under both delamination conditions. Experiments were then conducted to validate the proposed model.

\section{Analytical model}

\subsection{Analysis of drilling process and delamination mechanism}

Fig. 1 illustrates the tool geometry of a brad drill and the cutting processes in drilling of AFRP. The brad drill consists of the brad point, the cutting lips, and the cutting spurs at the outskirt of the cutting lips. The material removal can be divided into three stages: (I) The brad point and part of the cutting lips cut into the laminate successively. The brad point can lock the drill bit and prevent skating. (II) The cutting spurs penetrate the entrance plane of the AFRP laminate, and the rest of the cutting lips start to engage. (III) Under the cutting action of the cutting spurs and cutting lips, the aramid fiber bundles under the cutting lips is separated from the unmachined region (i.e., material outside the hole).
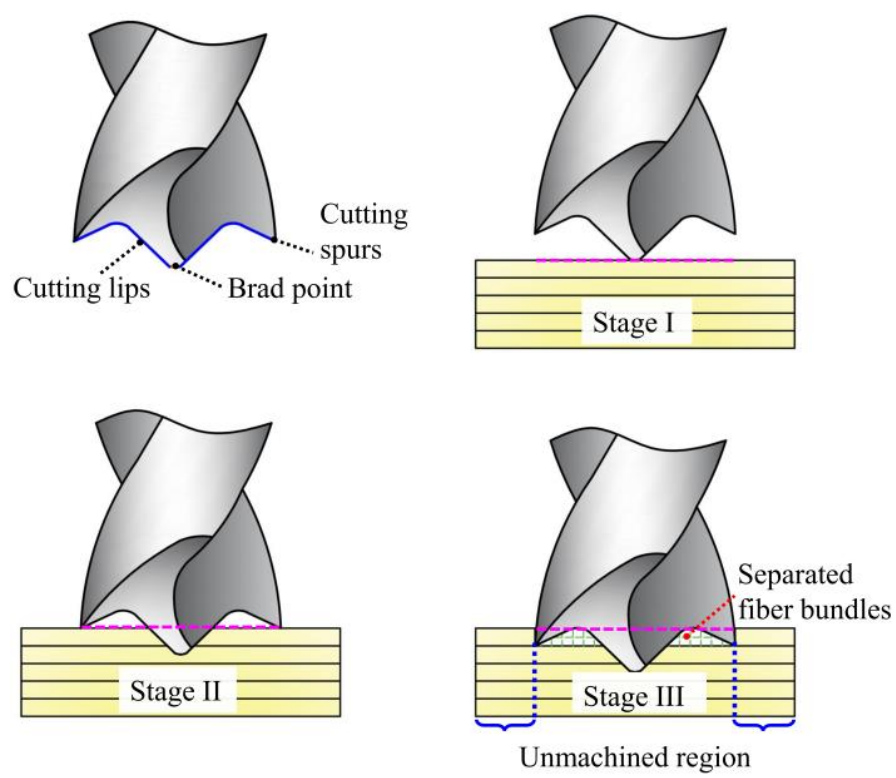

Fig. 1. Schematic showing the brad drill cutting process in drilling of AFRP. 
Fig. 2 illustrates the thrust force distribution in stage III of AFRP drilling. $F_{b}, F_{l}$, and $F_{s}$ are the thrust forces generated by the brad point, cutting lips, and cutting spurs, respectively, and the total thrust force generated by brad drill is the sum of the three components:

$$
F=F_{b}+F_{l}+F_{s}
$$

The ratios of different components are defined as:

$$
\alpha_{1}=\frac{F_{b}}{F} \quad \alpha_{2}=\frac{F_{s}}{F} \quad 1-\alpha_{1}-\alpha_{2}=\frac{F_{l}}{F}
$$

As can be seen from Figure 2, the uncut material consists of 3 regions. The uncut material under the brad point (Region 1 ) is subjected to $F_{b}$. Delamination initiates from the contact point between the tool cutting edge and hole wall, and propagates into the unmachined region along the fibers/resin interface. Since the material in Region 3 has been separated from the unmachined region by the cutting spurs, the effect of Region 3 on delamination is considered negligible. Moreover, it can be assumed that $F_{l}$ is transmitted to the uncut material under the cutting spurs (Region 2) through Region 3. Therefore, Region 2 is subjected to both $F_{l}$ and $F_{s}$.

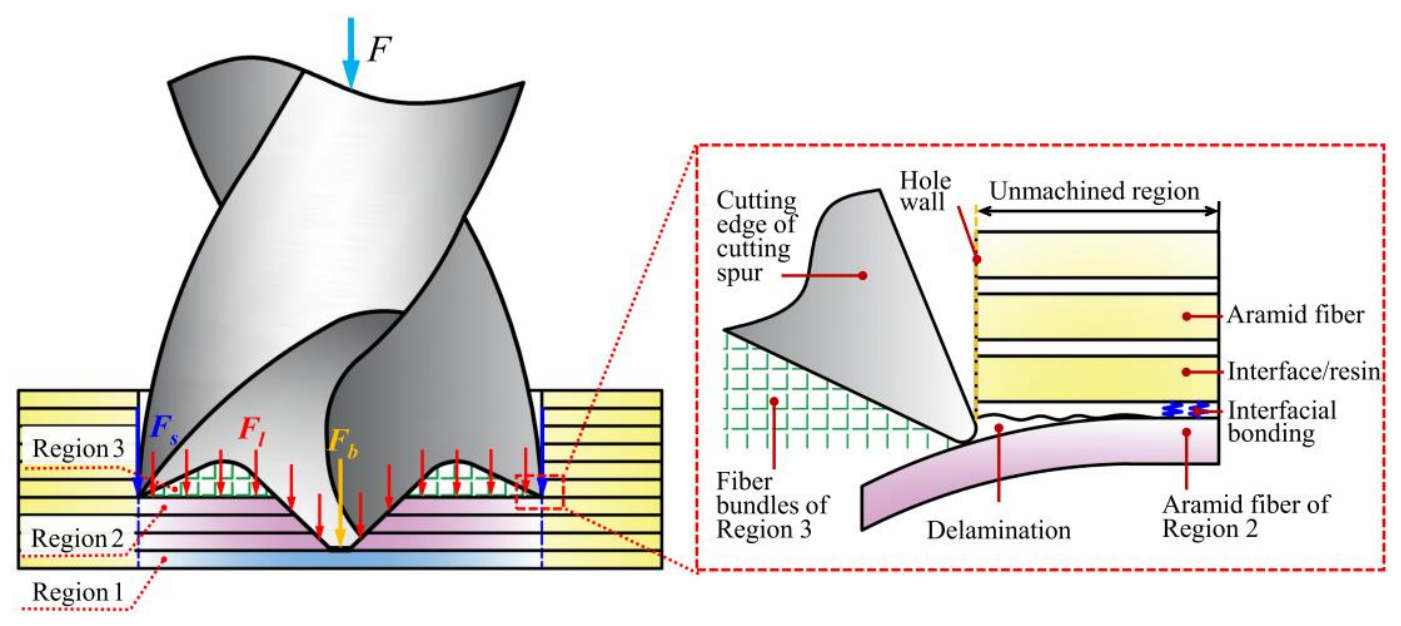

Fig. 2. The thrust force distribution in stage III in drilling of AFRP with brad drill. 
The hole exit and the hole wall are the sites most prone to delamination during the drilling process. It can be assumed that the initiation and propagation of the two types of delamination are independent [31]. The following analysis was carried out based on the hypothesis of linear elastic behaviour of the laminate and the principle of superimposition [8-9].

The mechanism of the hole wall delamination is shown in Fig. 3. As drilling progresses, Region 1 bending stiffness decreases with reducing material thickness and so is its support to Region 2. Under the combined action of $F_{l}$ and $F_{s}$, Region 2 experiences elastic deformation. At the cutting spur and hole wall contact, delamination crack will occur and propagate into the unmachined region as soon as the thrust force exceeds the critical value, leading to onset of hole wall delamination. For the hole wall delamination, the total CTF generated by the entire brad drill $F_{H W}$ can be described as follows:

$$
F_{H W}=\frac{F_{l}}{1-\alpha_{1}-\alpha_{2}}
$$

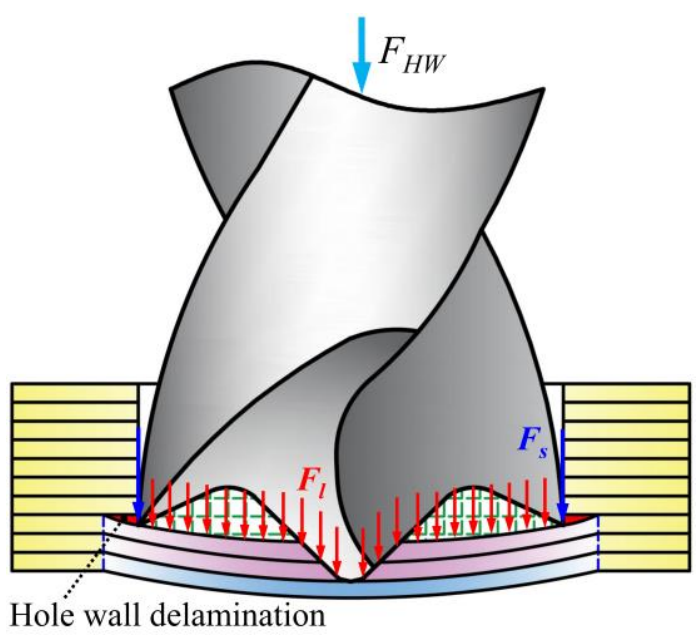

Fig. 3. Schematic diagram showing the hole wall delamination mechanism.

Fig. 4 shows the mechanism of the hole exit delamination, whose occurrence mainly depends on the thickness of Region 1. $F_{b}$ was modelled as a point load applied at the center of Region 1. As the thickness of Region 1 decreases, the reduction in Region 1 
bending stiffness facilitates the hole exit delamination. When $F_{b}$ reaches the AFRP interlaminar bonding strength, the hole exit delamination will occur and propagate. For the hole exit delamination, the total CTF generated by the entire brad drill $F_{H E}$ can be described as follows:

$$
F_{H E}=\frac{F_{b}}{\alpha_{1}}
$$

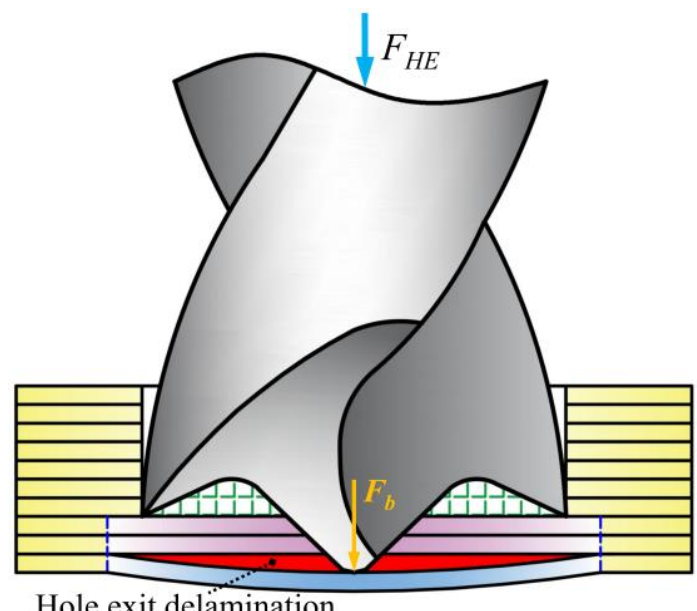

Fig. 4. Schematic showing the hole exit delamination mechanism.

\subsection{Modelling methodology}

In drilling of woven AFRP laminates, the uncut material can be modelled as orthotropic circular plates with constrained boundaries. The thrust force generated by the brad drill is normal to the circular plate. According to the classic plate bending theory [32], an element within the circular plate in equilibrium can be expressed as:

$$
D\left(\frac{d \varphi}{d r}+\frac{v}{r} \varphi\right)+\frac{d}{d r}\left[D\left(\frac{d \varphi}{d r}+\frac{v}{r} \varphi\right)\right] r-D\left(\frac{d \varphi}{d r} v+\frac{\varphi}{r}\right)+Q r=0
$$

where $\varphi$ is the slope of the plate deflection surface, $v$ is the Poisson's ratio, and $Q$ is the shear force per unit length of the element induced by the thrust force. The bending stiffness of the circular plate $D$ is as follows:

$$
D=\frac{1}{8}\left(3 D_{11}+2 D_{12}+4 D_{66}+3 D_{22}\right)
$$


where $D_{i j}$ is the coefficient of the bending stiffness matrix.

It should be noted that Eq. (5) is a general formula, where slope and deflection of the plate can be obtained under varying stress conditions and boundary conditions, thus the work done by the thrust force and the strain energy stored can be calculated. As the thrust force exceeds the critical value, delamination occurs. Based on LEFM, the criterion for the onset of delamination can be expressed as:

$$
\delta W=\delta U+\delta U_{d}
$$

where $\delta W$ is the external work done by the thrust force, $\delta U$ is the infinitesimal strain energy stored, and $\delta U_{d}$ is the variation of the strain energy due to delamination propagation.

Due to the special brad drill tool geometry, the work done by the external thrust forces and the stored strain energy can be modeled based on the actual drill / material contact and the corresponding force distribution. In the following sections, this modeling approach has been applied to both hole wall and hole exit delamination conditions.

2.3 Hole wall delamination

\subsubsection{Model formulation}

Fig. 5 shows the schematic diagram of Region 2 in the case of hole wall delamination. Considering the brad drill / material contact and the different thrust force distribution, Region 2 can be further decomposed into three components: (i) an annular plate with linearly varying thickness (APLVT), and (ii and iii) two annular plates with equal thickness. In addition, $R_{1}, R_{2}$, and $R_{3}$ are the inner radius of sections (i), (ii), and (iii), respectively. $a_{H W}$ is the radius of the initial hole wall delamination area. 

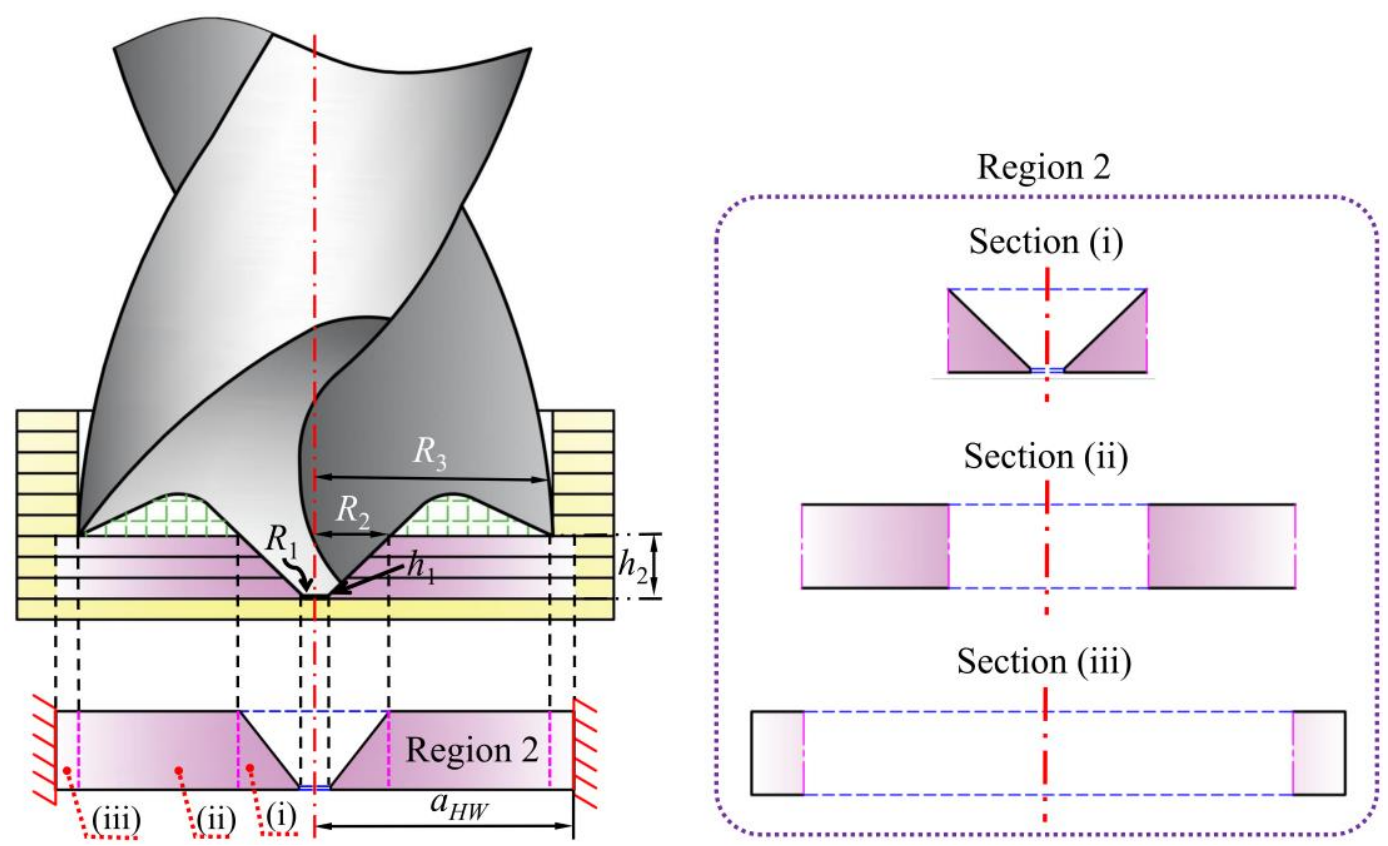

Fig. 5. Model of Region 2 for hole wall delamination.

Fig. 6 illustrates the thrust force distribution of section (i). Thrust force generated by the cutting lips can be assumed as uniformly distributed force $q$ exerting on section (i). Theoretically, section (i) can be modeled as an APLVT, and $h_{1}$ and $h_{2}$ are the height of the inner and the outer surface of section (i), respectively. In the case of an annular plate, $Q$ of section (i) can be expressed as:

$$
Q=\frac{1}{r} \int_{R_{1}}^{r} r q d r
$$

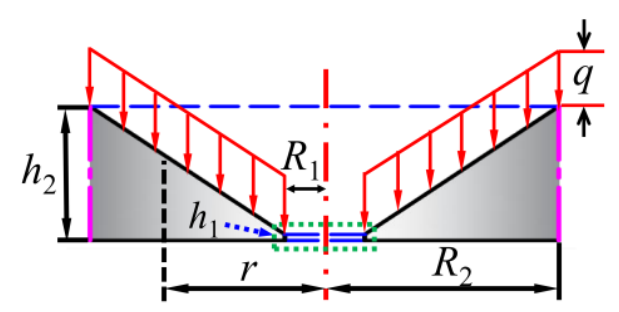

Fig. 6. Thrust force analysis of section (i).

Considering the bending stiffness of section (i), $D_{S 1}$ varies with $r$, and by substituting Eq. (8) into Eq. (5), the equilibrium equation for an unit element in section (i) can be obtained as follows: 


$$
D_{S 1} \frac{d}{d r}\left(\frac{d \varphi}{d r}+\frac{\varphi}{r}\right)+\frac{d D_{S 1}}{d r}\left(\frac{d \varphi}{d r}+v \frac{\varphi}{r}\right)=-\frac{1}{r} \int_{R_{1}}^{r} q r d r
$$

By solving for general solutions of the Euler equation, the slope of the section (i) deflection surface $\varphi_{S 1}$, and its deflection, $w_{S 1}$, can be obtained:

$$
\begin{gathered}
\varphi_{S 1}=C_{1} r^{\xi_{1}}+C_{2} r^{\xi_{2}}+q \xi_{3}-\frac{q \xi_{4}}{r^{2}} \\
w_{S 1}=-\frac{C_{1} r^{\xi_{1}+1}}{\xi_{1}+1}-\frac{C_{2} r^{\xi_{2}+1}}{\xi_{2}+1}-\xi_{3} q r-\frac{\xi_{4} q}{r}+C_{3}
\end{gathered}
$$

where $C_{i}$ is the integration constant, and the coefficient $\xi_{i}$ can be expressed as:

$$
\left\{\begin{array}{l}
\xi_{1}=\sqrt{3.25-3 v}-1.5 \\
\xi_{2}=-\sqrt{3.25-3 v}-1.5 \\
\xi_{3}=\frac{R_{1}^{3}}{2 D_{h 1}(1-3 v)} \\
\xi_{4}=\frac{R_{1}^{5}}{6 D_{h 1}(1-v)}
\end{array}\right.
$$

where $D_{h 1}$ is the bending stiffness with the height of $h_{1}$.

As for section (i), the stored strain energy and the work done by $q$ are described by equations Eqs. (13) - (14), respectively:

$$
\begin{gathered}
U_{S 1}=\frac{D_{h 1} \pi}{R_{1}^{3}} \int_{R_{1}}^{R_{2}}\left[\left(\frac{d^{2} w_{S 1}}{d r^{2}}+\frac{1}{r} \frac{d w_{S 1}}{d r}\right)^{2}-2(1-v)\left(\frac{d^{2} w_{S 1}}{d r^{2}} \times \frac{1}{r} \frac{d w_{S 1}}{d r}\right)\right] r^{4} d r \\
W_{S 1}=\int_{0}^{2 \pi} \int_{R_{1}}^{R_{2}} q w_{S 1} r \mathrm{~d} r \mathrm{~d} \theta
\end{gathered}
$$

As shown in Fig. 7, section (ii) with thickness $h_{2}$ is also subjected to $q$. Based on Eq. (5), the equilibrium equation for a unit element in section (ii) can be described as:

$$
D_{h 2} \frac{d}{d r}\left(\frac{d \varphi}{d r}+\frac{\varphi}{r}\right)+D_{h 2} \frac{d}{d r}\left(\frac{d \varphi}{d r}+v \frac{\varphi}{r}\right)=-\frac{1}{r} \int_{R_{2}}^{r} q r d r
$$




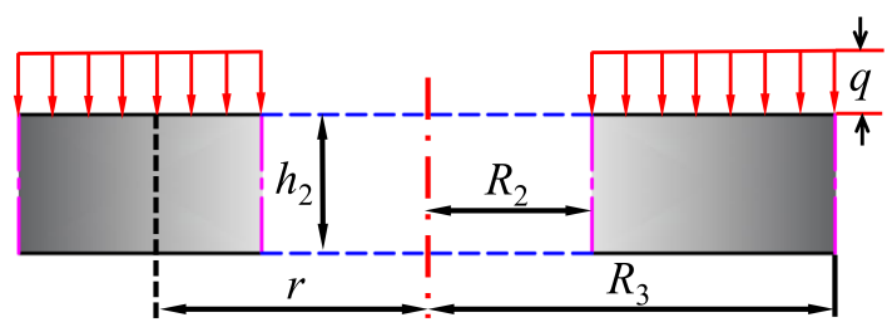

Fig. 7. Thrust force analysis of section (ii).

Following the similar procedures for $\varphi_{S 1}$, the slope of the section (ii) deflection surface $\varphi_{S 2}$ can be obtained:

$$
\varphi_{S 2}=C_{4} r+\frac{C_{5}}{r}-\frac{q r^{3}}{16 D_{h 2}}+\frac{q R_{2}^{2} r}{4 D_{h 2}} \ln r
$$

By integrating Eq. (16), the deflection of section (ii) $w_{S 2}$ can be described as:

$$
w_{S 2}=-\frac{C_{4} r^{2}}{2}-C_{5} \ln r+\frac{q r^{4}}{64 D_{h 2}}-\frac{q R_{2}^{2} r^{2}}{8 D_{h 2}}(\ln r-0.5)+C_{6}
$$

For section (ii), the stored strain energy under the action of cutting lips is:

$$
U_{S 2}=D_{h 2} \pi \int_{R_{2}}^{R_{3}}\left[\left(\frac{d^{2} w_{S 2}}{d r^{2}}+\frac{1}{r} \frac{d w_{S 2}}{d r}\right)^{2}-2(1-v)\left(\frac{d^{2} w_{S 2}}{d r^{2}} \times \frac{1}{r} \frac{d w_{S 2}}{d r}\right)\right] r d r
$$

And the work done by $q$ :

$$
W_{S 2}=\int_{0}^{2 \pi} \int_{R_{2}}^{R_{3}} q w_{S 2} r \mathrm{~d} r \mathrm{~d} \theta
$$

The analysis of the force distribution of section (iii) is shown in Fig. 8. The shear force $Q^{\prime}=F_{s} /\left(2 \pi R_{3}\right)$ is uniformly distributed along the inner edge of section (iii). The shearing force per unit length of circumference with radius $r$ can be described as:

$$
Q=\frac{F_{s}}{2 \pi r}
$$

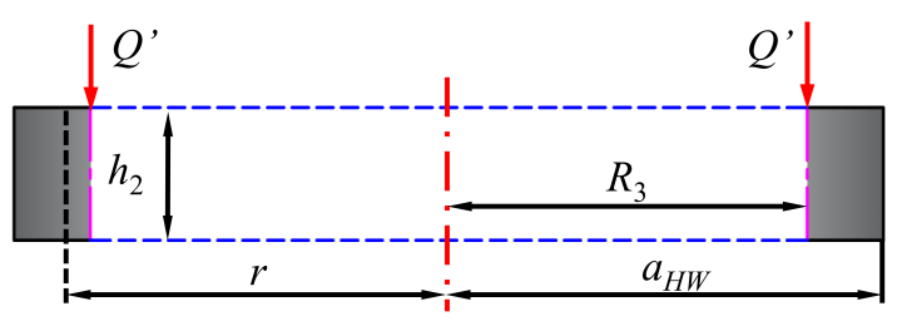


Fig. 8. Thrust force analysis of section (iii).

By substituting Eq. (20) into Eq. (5) and following subsequent integration, the slope of the deflected surface in section (iii), $\varphi_{S 3}$, is:

$$
\varphi_{S 3}=\frac{C_{7} r}{2}+\frac{C_{8}}{r}-\frac{F_{s} r}{4 \pi D_{h 2}}\left(\ln \frac{r}{a_{H W}}-0.5\right)
$$

By integrating Eq (21), the deflection of section (iii), $w_{S 3}$, can be expressed as:

$$
w_{S 3}=-\frac{C_{7} r^{2}}{4}-C_{8} \ln \frac{r}{a_{h w}}+\frac{F_{s} r^{2}}{8 \pi D_{h 2}}\left(\ln \frac{r}{a_{H W}}-1\right)+C_{9}
$$

The stored strain energy of section (iii) subjected to the action of the cutting spurs follows:

$$
U_{S 3}=D_{h 2} \pi \int_{R_{3}}^{a_{H W}}\left[\left(\frac{d^{2} w_{S 3}}{d r^{2}}+\frac{1}{r} \frac{d w_{S 3}}{d r}\right)^{2}-2(1-v)\left(\frac{d^{2} w_{S 3}}{d r^{2}} \times \frac{1}{r} \frac{d w_{S 3}}{d r}\right)\right] r d r
$$

The work done by the cutting spurs is:

$$
W_{S 3}=2 \pi R_{3} Q^{\prime} w_{S 3}
$$

\subsubsection{Integration constants}

In order to obtain the integration constants $C_{i}(i=1 \sim 9)$, the boundary conditions and the continuity conditions have been analyzed in this section. As illustrated in Fig. 5, the slope and the deflection of Region 2 at $r=a_{H W}$ is zero due to the constrained boundary. In addition, considering the support of Region 1 to Region 2, the deflection of Region 1 and Region 2 can be considered the same for $r=R_{1}$. In this case, the boundary conditions for the delamination model can be written as:

$$
\left\{\begin{array}{l}
\varphi_{S 3}{ }^{\left(a_{H W}\right)}=0 \quad w_{S 3}{ }^{\left(a_{H W}\right)}=0 \\
w_{R 1}{ }^{\left(R_{1}\right)}=w_{S 1}{ }^{\left(R_{1}\right)}
\end{array}\right.
$$

where 


$$
\begin{aligned}
& \varphi_{S 3}{ }^{\left(a_{H W}\right)}=\frac{C_{7} a_{H W}}{2}+\frac{C_{8}}{a_{H W}}+\frac{F_{s} a_{H W}}{8 \pi D_{h 2}}=0 \\
& w_{S 3}^{\left(a_{H W}\right)}=-\frac{C_{7} a_{H W}{ }^{2}}{4}-\frac{F_{s} a_{H W}{ }^{2}}{8 \pi D_{h 2}}+C_{9}=0 \\
& w_{R 1}{ }^{\left(R_{1}\right)}-w_{S 1}{ }^{\left(R_{1}\right)}=-\frac{C_{1} R_{1}^{\xi_{1}+1}}{\xi_{1}+1}-\frac{C_{2} R_{1}^{\xi_{2}+1}}{\xi_{2}+1}-\xi_{3} q R_{1}-\frac{\xi_{4} q}{R_{1}}+C_{3} \\
& -\frac{F_{b}}{16 \pi D_{R_{1}}}\left[2 R_{1}^{2} \ln \left(\frac{R_{1}}{a_{H E}}\right)+\left(a_{H E}^{2}-R_{1}^{2}\right)\right]=0
\end{aligned}
$$

Moreover, due to the overall contribution of continuous drill bit moment, the slope, and the deflection of Region 2, the continuity conditions at the interfaces between different parts of Region 2 can be described as:

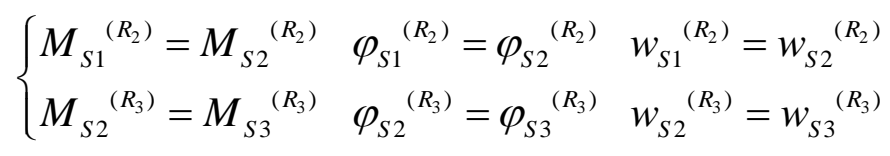

where

$$
\begin{aligned}
& M_{S 1}{ }^{\left(R_{2}\right)}-M_{S 2}{ }^{\left(R_{2}\right)}= \\
& C_{1} \xi_{1} R_{2}^{\xi_{1}-1}+C_{2} \xi_{2} R_{2}^{\xi_{2}-1}+\frac{v}{R_{2}}\left(C_{1} R_{2}^{\xi_{1}}+C_{2} R_{2}^{\xi_{2}}+\xi_{3} q-\frac{\xi_{4} q}{R_{2}^{2}}\right)+\frac{2 \xi_{4} q}{R_{2}^{3}} \\
& -\left[C_{4}-\frac{C_{5}}{R_{2}{ }^{2}}+\frac{R_{2}{ }^{2} q}{16 D_{h 2}}+\frac{v}{R_{2}}\left(C_{4} R_{2}+\frac{C_{5}}{R_{2}}-\frac{R_{2}{ }^{3} q}{16 D_{h 2}}+\frac{R_{2}{ }^{3} q \ln R_{2}}{4 D_{h 2}}\right)+\frac{R_{2}{ }^{2} q \ln R_{2}}{4 D_{h 2}}\right] \\
& =0 \\
& M_{S 2}{ }^{\left(R_{3}\right)}-M_{S 3}{ }^{\left(R_{3}\right)}= \\
& C_{4}-\frac{C_{5}}{R_{3}{ }^{2}}+\frac{R_{2}^{2} q}{4 D_{h 2}}-\frac{3 R_{3}^{2} q}{16 D_{h 2}}+\frac{v}{R_{3}}\left(C_{4} R_{3}+\frac{C_{5}}{R_{3}}-\frac{R_{3}^{3} q}{16 D_{h 2}}+\frac{R_{2}^{2} R_{3} q \ln R_{3}}{4 D_{h 2}}\right)+\frac{R_{2}^{2} q}{4 D_{h 2}} \ln R_{3}- \\
& {\left[\frac{C_{7}}{2}-\frac{C_{8}}{R_{3}^{2}}-\frac{F_{s}}{4 D_{h 2} \pi}+\frac{v}{R_{3}}\left(\frac{C_{7} C_{8}}{2}+\frac{C_{8}}{R_{3}}-\frac{F_{s} R_{3}}{4 D_{h 2} \pi}\left(\ln \frac{R_{3}}{a_{H W}}-\frac{1}{2}\right)\right)-\frac{F_{s}}{4 D_{h 2} \pi}\left(\ln \frac{R_{3}}{a_{H W}}-\frac{1}{2}\right)\right]} \\
& =0 \\
& -\left[C_{4} R_{2}+\frac{C_{5}}{R_{2}}-\frac{R_{2}^{3} q}{16 D_{h 2}}+\frac{R_{2}^{3} q}{4 D_{h 2}} \ln R_{2}\right]=0
\end{aligned}
$$




$$
\begin{gathered}
\varphi_{S 2}{ }^{\left(R_{3}\right)}-\varphi_{S 3}{ }^{\left(R_{3}\right)}=C_{4} R_{3}+\frac{C_{5}}{R_{3}}-\frac{q R_{3}{ }^{3}}{16 D_{h 2}}+\frac{q R_{2}{ }^{2} R_{3}}{4 D_{h 2}} \ln R_{3} \\
-\left[\frac{C_{7} R_{3}}{2}+\frac{C_{8}}{R_{3}}-\frac{F_{s} R_{3}}{4 \pi D_{h 2}}\left(\ln \frac{R_{3}}{a_{H W}}-0.5\right)\right]=0 \\
w_{S 1}{ }^{\left(R_{2}\right)}-w_{S 2}{ }^{\left(R_{2}\right)}=-\frac{C_{1} R_{2}{ }^{\xi_{1}+1}}{\xi_{1}+1}-\frac{C_{2} R_{2}{ }^{\xi_{2}+1}}{\xi_{2}+1}-\xi_{3} q R_{2}-\frac{\xi_{4} q}{R_{2}}+C_{3} \\
+\frac{C_{4} R_{2}{ }^{2}}{2}+C_{5} \ln R_{2}-\frac{q R_{2}{ }^{4}}{64 D_{h 2}}+\frac{q R_{2}{ }^{4}}{8 D_{h 2}}\left(\ln R_{2}-0.5\right)-C_{6}=0 \\
w_{S 2}{ }^{\left(R_{3}\right)}-w_{S 3}{ }^{\left(R_{3}\right)}=- \\
-\left[-\frac{C_{4} R_{3}{ }^{2}}{2}-C_{5} \ln R_{3}+\frac{q R_{3}{ }^{4}}{64 D_{h 2}}-\frac{q R_{2}^{2} R_{3}{ }^{2}}{8 D_{h 2}}\left(\ln R_{3}-0.5\right)+C_{6}\right. \\
\left.4 \ln \frac{R_{3}}{a_{H W}}+\frac{F_{s} R_{3}{ }^{2}}{8 \pi D_{h 2}}\left(\ln \frac{R_{3}}{a_{H W}}-1\right)+C_{9}\right]=0
\end{gathered}
$$

Therefore, the integration constants $C_{i}(i=1 \sim 9)$ can be calculated by combining Eqs. (26)-(28) and (30)-(35).

\subsubsection{CTF for hole wall delamination}

Region 2 consists of three sections (i, ii, iii), which are subjected to the combined action of $q$ and $F_{\mathrm{s}}$. Therefore, the total stored strain energy in Region 2 for the hole wall delamination $U_{H W}$ can be expressed as:

$$
\delta U_{H W}=\frac{\partial\left(U_{S 1}+U_{S 2}+U_{S 3}\right)}{\partial a_{H W}} \delta a_{H W}
$$

Moreover, the work done by $q$ and $F_{\text {s }}$ on Region 2 follows:

$$
\delta W_{H W}=\frac{\partial\left(W_{S 1}+W_{S 2}+W_{S 3}\right)}{\partial a_{H W}} \delta a_{H W}
$$

The virtual variation of delamination energy for the hole wall delamination can be expressed as:

$$
\delta U_{d}{ }^{H W}=G_{I C} 2 \pi a_{H W} \delta a_{H W}
$$

where $G_{I C}$ is the energy release rate in mode I.

By substitution Eq. (36)-(38) into Eq. (7) and calculation of $q$, the critical value of $F_{l}$ generated by the cutting lips can be obtained for the hole wall delamination: 


$$
F_{l}=q \pi\left(R_{3}^{2}-R_{1}^{2}\right)
$$

\subsection{Hole exit delamination}

Fig. 9 illustrates the thrust force distribution of Region 1 for the hole exit delamination. Due to the short length of the brad point, $F_{b}$ can be considered as a concentrated force exerting on the center of Region 1. $a_{H E}$ is the radius of the initial hole exit delamination area. Based on Eq (5), the deflection of Region 1 for the hole exit delamination can be described as follows:

$$
w_{H E}=\frac{F_{\mathrm{c}}}{16 \pi D_{R 1}}\left[2 r^{2} \ln \left(\frac{r}{a_{H E}}\right)+\left(a_{H E}^{2}-r^{2}\right)\right]
$$

where $D_{R 1}$ is the bending stiffness of Region 1 .

Moreover, the work done by $F_{b}$, the stored strain energy of Region 1, and the strain energy absorbed by the hole exit delamination propagation can be expressed as:

$$
\left\{\begin{array}{l}
\delta W_{H E}=\frac{F_{b}^{2} a_{H E}}{8 \pi D_{R 1}} \delta a_{H E} \\
\delta U_{H E}=\frac{F_{b}^{2} a_{H E}}{16 \pi D_{R 1}} \delta a_{H E} \\
\delta U_{d}^{H E}=G_{I C} 2 \pi a_{H E} \delta a_{H E}
\end{array}\right.
$$

When substituting the above expressions into Eq. (7), the CTF generated by the brad point for the hole exit delamination can be obtained:

$$
F_{b}=\pi \sqrt{32 G_{\mathrm{IC}} D_{R 1}}
$$




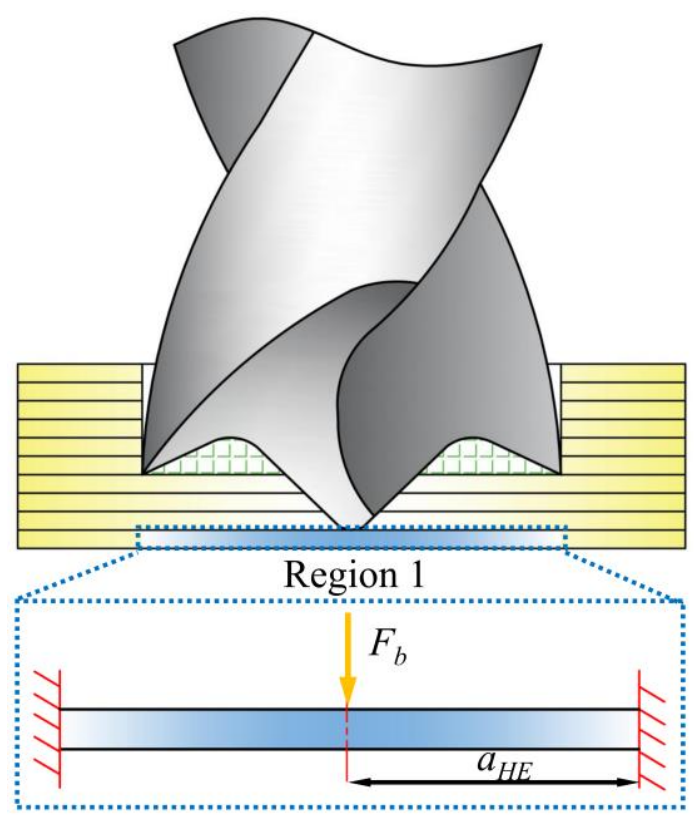

Fig. 9. Model of Region 1 for the hole exit delamination.

\section{Experiments}

The AFRP laminates used in this study are made of plain-woven aramid/epoxy prepregs with $60 \mathrm{vol} \%$ fiber fraction. The fabrication of the AFRP laminate follows the preciously established method [30]. More specifically, AFRP laminates were cured in an autoclave at $115^{\circ} \mathrm{C}$ for $60 \mathrm{~min}$, and then at $180^{\circ} \mathrm{C}$ for $120 \mathrm{~min}$. The laminates consist of 15 plies (single ply thickness $=0.27 \mathrm{~mm}$ ). After curing, the AFRP laminates were cut into $160 \mathrm{~mm} \times 100 \mathrm{~mm}$ coupons for drilling experiments. The mechanical properties of the AFRP laminates are listed in Table $1[29,31]$.

Table 1 Properties of AFRP composite laminates

\begin{tabular}{lllll}
\hline$E_{11}(\mathrm{MPa})$ & $E_{22}(\mathrm{MPa})$ & $G_{12}(\mathrm{MPa})$ & $v_{12}$ & $G_{I C}\left(\mathrm{~J} / \mathrm{m}^{2}\right)$ \\
\hline 18000 & 18000 & 770 & 0.25 & 295.95 \\
\hline
\end{tabular}

Fig. 10 illustrates the experimental setup where a XK714D computer numerical control machine tool was used for dry drilling with a brad drill. During drilling, the thrust force was recorded using a dynamometer (9257B, Kistler), a charge amplifier (5070A, Kistler), and a data acquisition card. The data were processed by the program Dynoware. The brad drill is made of $6 \mathrm{~mm}$ diameter solid carbide, and the geometric 
parameters of the brad drill are listed in Table 2.

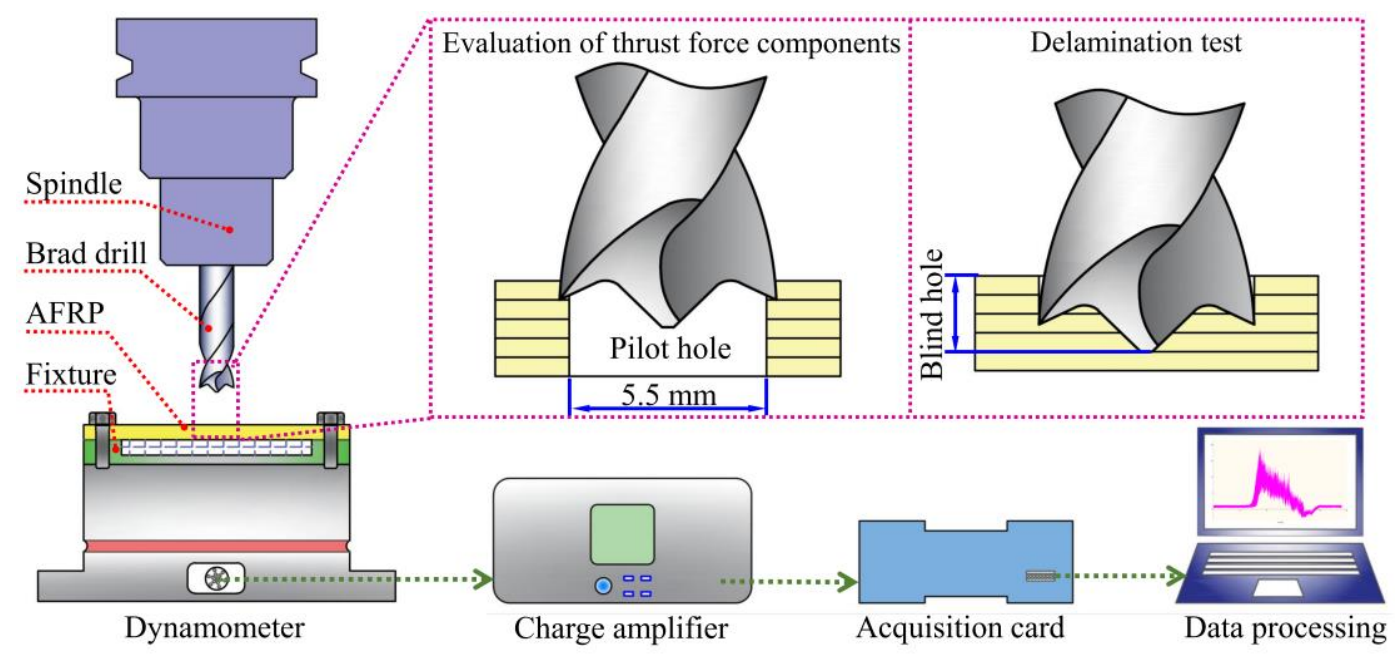

Fig. 10. Experimental setup for the thrust force evaluation and delamination test.

Table 2 Geometric parameters of the brad drill

\begin{tabular}{lllll}
\hline$R_{1}(\mathrm{~mm})$ & $R_{2}(\mathrm{~mm})$ & $R_{3}(\mathrm{~mm})$ & $h_{1}(\mathrm{~mm})$ & $h_{2}(\mathrm{~mm})$ \\
\hline 0.125 & 0.95 & 3 & 0.1 & 0.76 \\
\hline
\end{tabular}

In order to precisely validate the proposed delamination model, it is important to evaluate the contributions of thrust forces generated by different cutting edges of the brad drill. The time axis of the thrust force curve is related to the height of the drill engaged in the drilling process. The height of the brad point $\left(h_{1}\right)$ is listed in Table 2. Therefore, during drilling of AFRP laminates, the thrust force ratio of the brad point $\left(\alpha_{1}\right)$ can be obtained by analyzing the measured thrust force curves. Moreover, a pilot hole with a diameter of $5.5 \mathrm{~mm}$ was drilled to evaluate the load on the cutting spurs. By comparing the thrust forces with and without pilot holes, the thrust force ratio of the cutting spurs $\left(\alpha_{2}\right)$ can be obtained. The evaluation tests were conducted under a spindle speed of $2000 \mathrm{rpm}$ and a feed rate of $5 \mathrm{~mm} / \mathrm{min}$. The contribution of thrust force components generated by different cutting edges has been summarized in Table 3 . Furthermore, blind holes were drilled with different Region 1 thickness $(0.135 \mathrm{~mm}$ and $0.27 \mathrm{~mm}$, respectively), see Fig. 10. The delamination tests were conducted at a feed rate of $5 \mathrm{~mm} / \mathrm{min}$, and each uncut thickness was repeated three times to confirm repeatability. 
Table 3 Experimental results of thrust force components of the brad drill.

\begin{tabular}{llllll}
\hline & $F_{b}(\mathrm{~N})$ & $F_{s}(\mathrm{~N})$ & $F(\mathrm{~N})$ & $\alpha_{1}$ & $\alpha_{2}$ \\
\hline Average value & 3.09 & 7.85 & 32.87 & $9.4 \%$ & $23.9 \%$ \\
Standard deviation & 0.11 & 0.64 & 0.13 & & \\
\hline
\end{tabular}

\section{Modeling validation}

Fig. 11shows the thrust force curve of delamination test (Region 1 thickness $=0.135$ $\mathrm{mm}$ ). The first abrupt drop of the thrust force (point A) represents the CTF of the hole wall delamination, which is caused by the interfacial fracture form the contact point between the cutting spurs and the machined surface. Once the thrust force exceeds the critical value, delamination crack will occur and propagate into the unmachined region. Since Region 2 is supported by Region 1, the thrust force rises rapidly after Point A. With further application of the thrust force, it can be observed that the thrust force curve increases quasi-linearly up to point $\mathrm{B}$, which corresponds to the total CTF of the hole exit delamination [15]. Since no support is available under Region 1 to restrain the hole exit delamination, the thrust force curve eventually drops when the test ends.

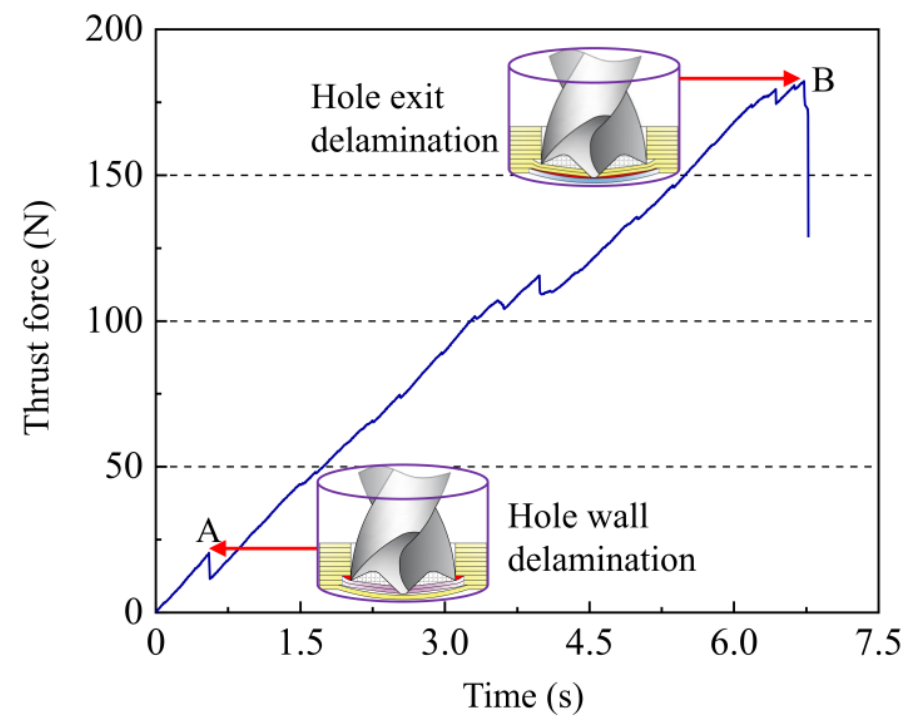

Fig. 11. Thrust force of delamination test for Region 1 with $0.135 \mathrm{~mm}$ thickness.

Fig. 12 compares the experimental data and the predictive values of CFTs for different Region 1 thickness. It can be seen that our proposed model agrees well with the experimental results. In the case of hole exit delamination (Region $1=0.27 \mathrm{~mm}$ ), 
the largest deviation from the experiments is $8.66 \%$. This might be due to the sharp brad point of the brad drill. With the increasing force applied by the drill, the thrust force experienced by Region 1 also increases. The sharp brad point hence tends to penetrate into the Region 1 material rather than punching through it during the delamination test, therefore a lower CTF for the hole wall delamination can be expected.

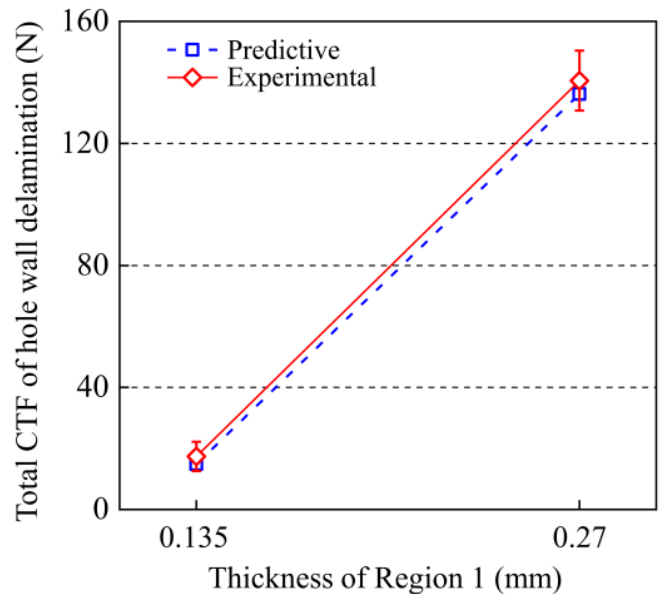

(a)

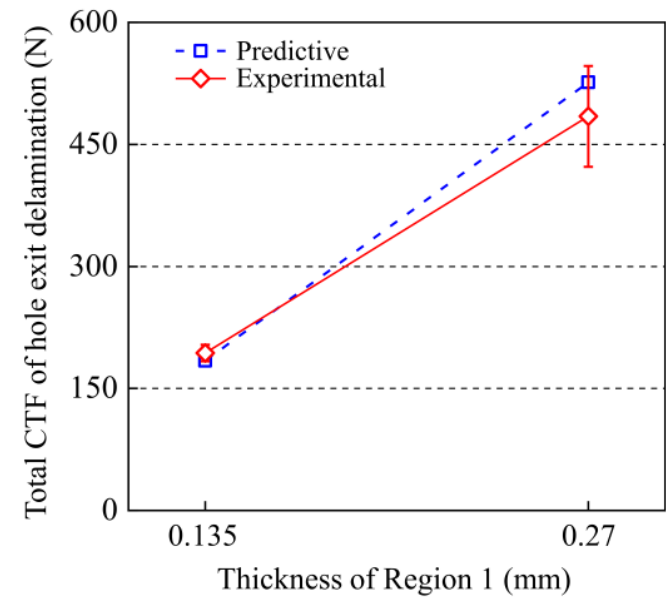

(b)

Fig. 12. Comparison of the predictive CTFs and the corresponding experimental data for (a) hole wall delamination, and (b) hole exit delamination.

\section{Modeling analysis}

Based on Eqs. (3) and (4), the comparison of the predictive CTFs in two different delamination scenarios is shown in Fig. 13. It can be seen that the predictive values of $F_{H E}$ and $F_{H W}$ both increase with increasing Region 1 thickness. The increase in $F_{H E}$ is the result of the increased Region 1 bending stiffness, while the increase in $F_{H W}$ is due to the increasing Region 1 thickness, which in turn leads to the enhanced supporting ability of Region 1 . When Region 1 thickness is less than $0.38 \mathrm{~mm}$, $F_{H E}>F_{H W}$. Under this condition, hole wall delamination is more likely to occur prior to hole exit delamination. In addition, it can be seen that $F_{H W}$ increases rapidly as Region 1 thickness exceeds $0.3 \mathrm{~mm}$. There is no hole wall delamination for Region 1 thickness exceeding $0.4 \mathrm{~mm}$, as this would require infinite $F_{H W}$. However, the 
predictive value of $F_{H W}$ drastically decreases from $136.18 \mathrm{~N}$ to $14.83 \mathrm{~N}$ when Region 1 thickness decreases from $0.27 \mathrm{~mm}$ to $0.135 \mathrm{~mm}$.

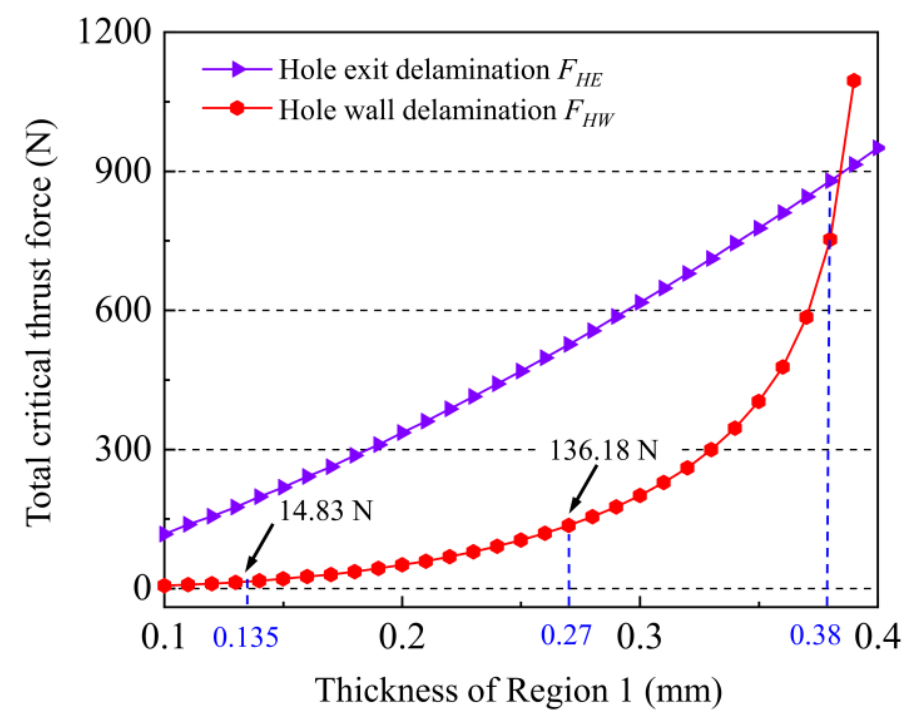

Fig. 13. Comparison of the predictive CTFs as a function of Region 1 thickness.

Fig. 14 shows a typical image of AFRP hole exit damage induced by the brad drill, whose feature can be well explained by the proposed model in this study. When drilling progressed to the exit plane, the cutting spurs first cut the outermost edge of the material under the tool. Due to the rapidly decreasing $F_{H W}$, the thrust force is likely to exceed the critical value, leading to hole wall delamination. The delaminated material was subjected to bending rather than being cut by the drill, which leads to the residual material seen near the hole exit.

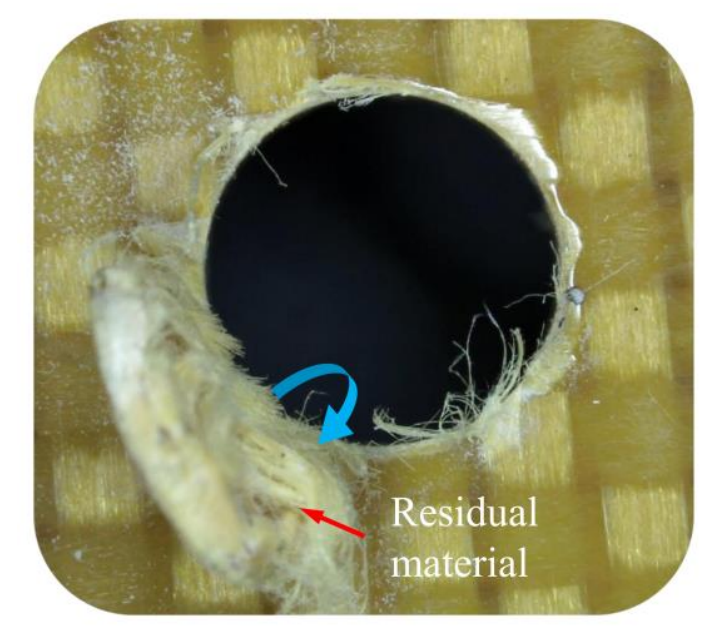

Fig. 14. Typical exit damage introduced by brad drill. 
Fig. 15 shows the influence of the ratios of the thrust force components on $F_{H W}$ for Region $1=0.27 \mathrm{~mm}$. Based on the experimental results in Table 3, the value of $F_{l} / F$, $F_{s} / F$, and $F_{b} / F$ are $66.7 \%, 23.9 \%$, and $9.4 \%$, respectively. As illustrated in Fig. 15(a), $F_{H W}$ increases significantly with increasing $F_{s} / F_{b}$. When the value of $F_{s} / F_{b}$ exceeds 8.5 , no hole wall delamination will occur. The evaluation for $F_{H W}$ with varying $F_{l} / F_{b}$ is shown in Fig. $15(b)$. It can be seen that $F_{H W}$ increases with increasing $F_{l} / F_{b}$. Therefore, increasing the contributions of the thrust force components $F_{s}$ and $F_{l}$ of the brad drill is beneficial for reducing the hole wall delamination. Furthermore, Fig. 15(c) shows that $F_{H W}$ increases with increasing $F_{s} / F_{l}$. Therefore, compared with the contribution of the cutting lips, the contribution of the cutting spurs is more effective in suppressing the hole wall delamination.

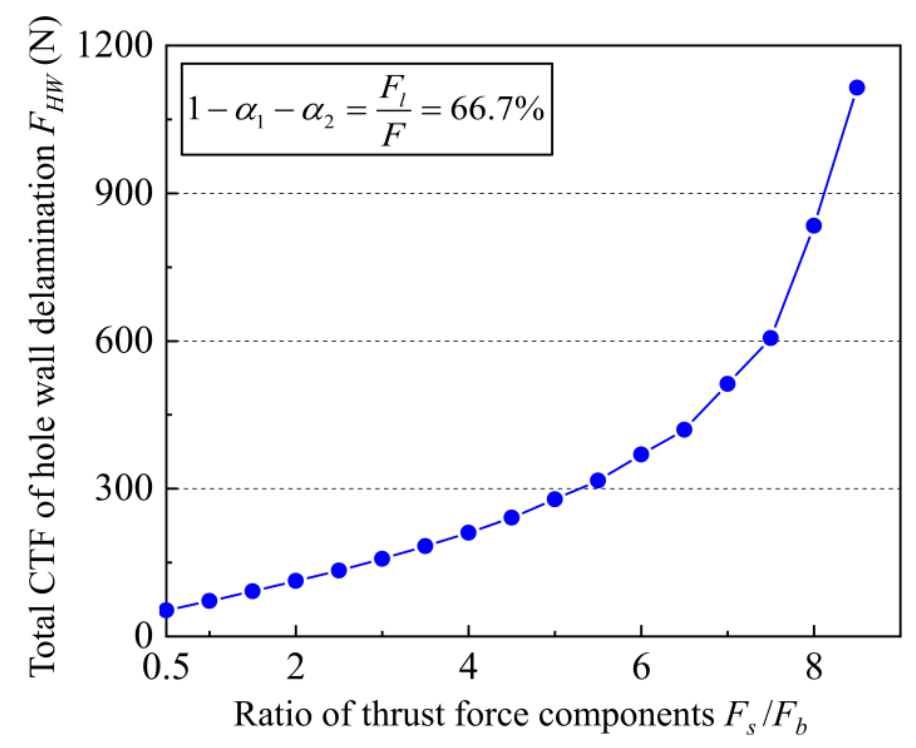

(a) 


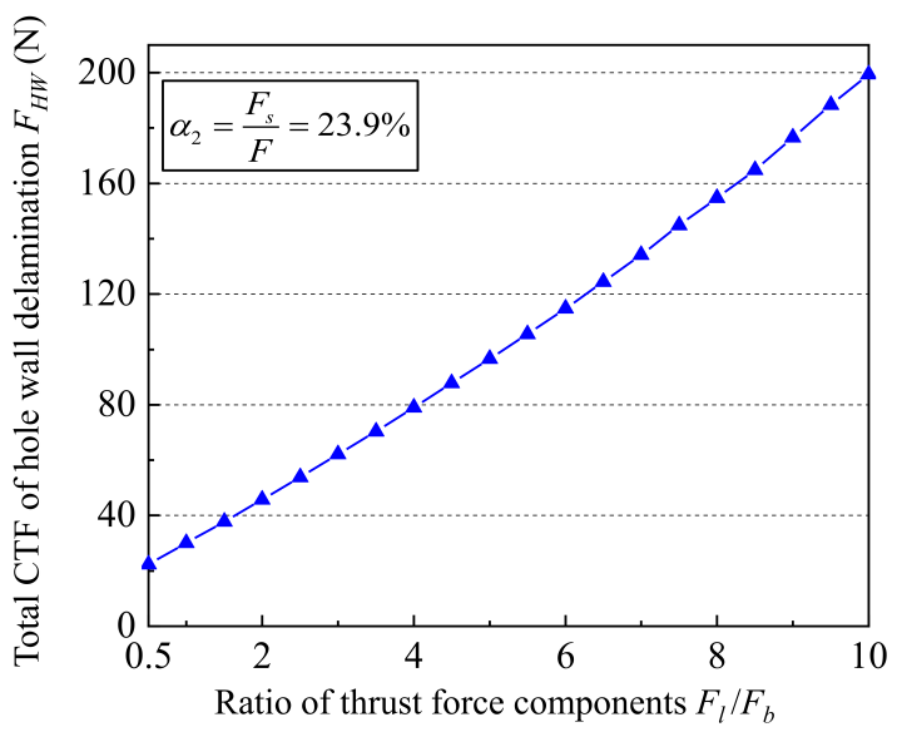

(b)

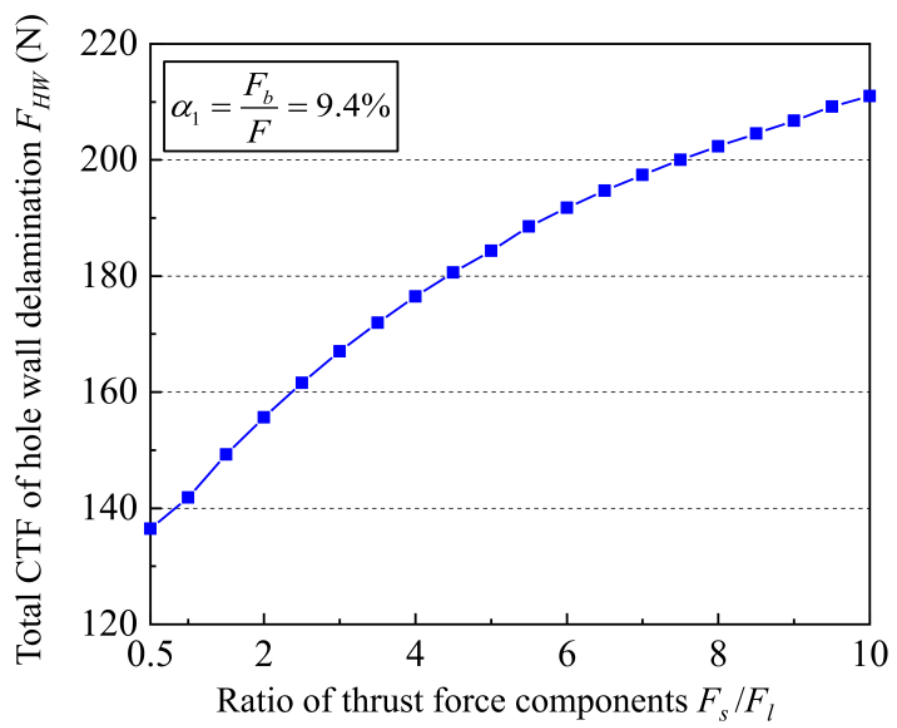

(c)

Fig. 15. The influence of the ratios of the thrust force components on $F_{H W}$ for Region 1 with 0.27 mm thickness.

With regard to the hole exit delamination, the influence of $\alpha_{1}$ on $F_{H E}$ for Region $1=0.27 \mathrm{~mm}$ is shown in Fig. 16. It can be seen that $F_{H E}$ decreases with increasing $\alpha_{1}$, which can be explained by Eq. (4). It can be concluded that lower $\alpha_{1}$ correlates to greater $F_{H E}$, which better restrains the hole exit delamination. 


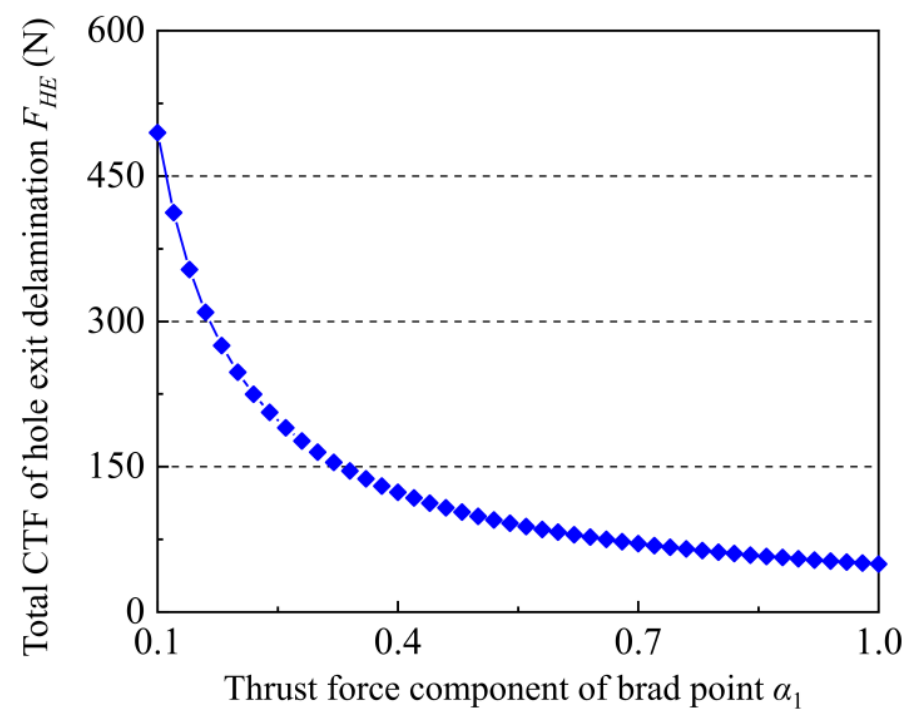

Fig. 16. The influence of thrust force component of brad point on $F_{H E}$ for Region 1 with $0.27 \mathrm{~mm}$ thickness.

\section{Conclusions}

This study presented an in-depth discussion on the AFRP drilling delamination regime. A novel delamination model has been proposed where the unique geometry of brad drill has been considered for the first time. Based on the actual tool / material contact conditions, two delamination mechanisms, namely, hole wall delamination and hole exit delamination have been introduced. The associated analytical models which accounts for thrust force components generated by the brad point, cutting lips, and cutting spurs of brad drill have been proposed for the CTF prediction for the two delamination mechanisms. The proposed model is validated by experiments, and the results showed that our model agrees well with the experimental data with the largest deviation from the experiments being $8.66 \%$.

CTF model analysis shows that the hole wall delamination is strongly influenced by the bending stiffness of uncut material under the brad point (Region 1). The hole wall delamination is more likely to occur prior to hole exit delamination when the thickness of Region 1 is less than $0.38 \mathrm{~mm}$. No hole wall delamination will occur when the thickness of Region 1 exceeds $0.4 \mathrm{~mm}$. However, the CTF of hole wall delamination drastically decreases from $136.18 \mathrm{~N}$ to $14.83 \mathrm{~N}$ when Region 1 thickness decreases 
from $0.27 \mathrm{~mm}$ to $0.135 \mathrm{~mm}$.

The influences of thrust force components generated by different cutting edges of a brad drill on the total CTF have been investigated in detail and it is found that the contribution of cutting spurs is more effective at suppressing hole wall delamination Since a certain percentage of thrust force is distributed along the periphery of the drill bit rather than concentrated in the center of the tool, the CTF is significantly increased, hence reducing delamination.

\section{Acknowledgments}

This project has received funding from the Natural Science Foundation of Tianjin (Grant No. 18JCQNJC75600), the National Natural Science Foundation of China (Grant No. 51705362), the Science \& Technology Development Fund of Tianjin Education Commission for Higher Education (Grant No. 2017KJ081), and the European Union's Horizon 2020 research and innovation program (Grant No. 734272). The authors also thank Chinese Scholarship Council for funding support (Contract No. 201808120102).

\section{References}

1. Isa MT, Ahmed AS, Aderemi BO, Taib RM, Mohammed-Dabo IA (2013) Effect of fiber type and combinations on the mechanical, physical and thermal stability properties of polyester hybrid composites. Compos Part B Eng 52:217-223

2. Sun D, Lemoine P, Keys D, Doyle P, Malinov S, Zhao Q, Qin XD, Jin Y (2016) Hole-making processes and their impacts on the microstructure and fatigue response of aircraft alloys. Int J Adv Manuf Technol 94:1719-1726

3. Liu SN, Yang T, Liu C, Jin Y, Sun D, Shen YF (2020) Mechanistic force modelling in drilling of AFRP composite considering the chisel edge extrusion. Int J Adv Manuf Technol, revision submitted.

4. Chouhan H, Singh D, Parmar V, Kalyanasundaram D, Bhatnagar N (2016) Laser machining of Kevlar fiber reinforced laminates - effect of polyetherimide versus polypropylene matrix. Compos Sci Technol 134:267-274 
5. Bao YJ, Hao W, Wang YQ, Gao H, Liu XS (2019) Formation mechanism of burr defect in aramid fiber composites based on fly-cutting test. Int J Adv Manuf Technol 104:1531-1540

6. Durão LMP, Gonçalves DJS, Tavares JMRS, Albuquerque VHCD, Marques AT (2011) Comparative analysis of drills for composite laminates. J Compos Mater 46(14):1649-1659

7. Saleem M, Zitoune R, El Sawi I, Bougherara H (2015) Role of the surface quality on the mechanical behavior of CFRP bolted composite joints. Int J Fatigue 80:246256

8. Girot F, Dau F, Gutiérrez-Orrantia ME (2017) New analytical model for delamination of CFRP during drilling. J Mater Process Tech 240:332-343

9. Zarif Karimi N, Minak G, Kianfar P (2015) Analysis of damage mechanisms in drilling of composite materials by acoustic emission. Compos Struct 131:107-114

10. Zarif Karimi N, Heidary H, Minak G, Fotouhi M (2017) Experimental analysis of GFRP laminates subjected to compression after drilling. Compos Struct 169:144152

11. Ho-Cheng H, Dharan CKH (1990) Delamination during drilling in composite laminates. J Eng Ind 112(3):236-239

12. Upadhyay P, Lyons J (1999) On the evaluation of critical thrust for delaminationfree drilling of composite laminates. J Reinf Plast Compos 18:1287-1303

13. Jain S, Yang DCH (1994) Delamination-free drilling of composite laminates. J Eng Ind 116:475-481

14. Zarif Karimi N, Heidary H, Minak G (2016) Critical thrust and feed prediction models in drilling of composite laminates. Compos Struct 148:19-26

15. Saoudi J, Zitoune R, Mezlini S, Gururaja S, Seitier P (2016) Critical thrust force predictions during drilling: Analytical modeling and X-ray tomography quantification. Compos Struct 153:886-894

16. Ismail SO, Ojo SO, Dhakal HN (2016) Thermo-mechanical modelling of FRP cross-ply composite laminates drilling: Delamination damage analysis. Compos Part B: Eng 108:45-52 
17. Ojo SO, Ismail SO, Paggi M, Dhakal HN (2017) A new analytical critical thrust force model for delamination analysis of laminated composites during drilling operation. Compos Part B 124:207-217

18. Rahmé P, Landon Y, Lachaud F, Piquet R, Lagarrigue P (2011) Analytical models of composite material drilling. Int J Adv Manuf Technol 52:609-617

19. Shuaib AN, Al-Sulaiman FA, Hamid F (2004) Machinability of Kevlar 49 composite laminates while using standard TiN coated HSS drills. Mach Sci Technol 8:449-467

20. Wang FJ, Qian BW, Jia ZY, Cheng D, Fu R (2018) Effects of cooling position on tool wear reduction of secondary cutting edge corner of one-shot drill bit in drilling CFRP. Int J Adv Manuf Technol 94:4277-4287

21. Tsao CC (2008) Prediction of thrust force of step drill in drilling composite materials by Taguchi method and radial basis function network. Int J Adv Manuf Technol 36:11-18

22. Qiu XY, Li PN, Li CP, Ni QL, Chen AH, Ouyang PR, Ko TJ (2018) Study on chisel edge drilling behavior and step drill structure on delamination in drilling CFRP. Compos Struct 203:404-413

23. Su F, Deng ZH, Sun F, Li SC, Wu QP, Jiang XJ (2019) Comparative analyses of damages formation mechanisms for novel drills based on a new drill-induced damages analytical model. J Mater Process Tech 271:111-125

24. Feito N, Muñoz-Sánchez A, Díaz-Álvarez A, Miguelez MH (2019) Multi-o bjective optimization analysis of cutting parameters when drilling composite materials with special geometry drills. Compos Struct. https://doi.org/10.10 16/j.compstruct.2019.111187

25. Díaz-Álvarez A, Díaz-Álvarez J, Santiuste C, Miguélez MH (2019) Experimental and numerical analysis of the influence of drill point angle when drilling biocomposites. Compos Struct 209:700-709

26. Hocheng H, Tsao CC. Effect of special drill bits on drilling-induced delamination of composite materials (2006) Int J Mach Tools Manuf 46:1403-1416

27. Jia ZY, Fu R, Niu B, Qian BW, Bai Y, Wang FJ (2016) Novel drill structure for 
damage reduction in drilling CFRP composites. Int J Mach Tools Manuf 110:5565

28. Di Ilio A, Tagliaferri V, Veniali F (1991) Cutting mechanisms in drilling of aramid composites. Int J Mach Tools Manuf 31(2):155-165

29. Díaz-Álvarez A, Rodríguez-Millán M, Díaz-Álvarez J, Miguélez MH (2018) Experimental analysis of drilling induced damage in aramid composites. Compos Struct 202:1136-1144

30. Liu SN, Yang T, Liu C, Du Y (2019) Comprehensive investigation of cutting mechanisms and hole quality in dry drilling woven AFRP with typical tools. Proc IMechE, Part B: J Engineering Manufacture 223(14):2471-2491

31. Liu SN, Yang T, Liu C, Jin Y, Sun D, Shen YF (2020) Modelling and experimental validation on drilling delamination of aramid fiber reinforced plastic composites. Compos Struct https://doi.org/10.1016/j.compstruct.2020.111907

32. Timoshenko S, Woinowsky-Krieger S (1959) Theory of plates and shells. McGraw-Hill 